\title{
Discutindo a indisciplina, a violência e o bullying na instituição escolar
}

\author{
Discussing the indiscipline, violence and bullying in school \\ Discutiendo la indisciplina, violencia y bullying en la escuela
}

\section{Leila Maria Torraca de Brito*}

Universidade do Estado do Rio de Janeiro - UERJ, Rio de Janeiro, Rio de Janeiro, Brasil

\section{Marisa Lopes da Rocha**}

Universidade do Estado do Rio de Janeiro - UERJ, Rio de Janeiro, Rio de Janeiro, Brasil

\begin{abstract}
RESUMO
Neste ensaio, procuramos apontar de que maneira a indisciplina, a violência escolar e o bullying vêm sendo enfocados na contemporaneidade. Mostramos também que a medicalização e a judicialização da vida são práticas que, além de ganharem maior visibilidade na sociedade, marcam forte presença no ambiente escolar. As redes de cuidado no ensino vêm priorizando tanto a medicalização como o tratamento dos alunos na condição de vítimas e de agressores. Concluímos evidenciando os seguintes pontos: (i) desinvestimento nas análises da (in)disciplina como efeito de um modo de organização das práticas escolares e nas mudanças do contexto educacional; (ii) enaltecimento do conceito de bullying; (iii) e implicação de profissionais da área de segurança no processo.

Palavras-chave: Indisciplina escolar, bullying, judicialização, medicalização.
\end{abstract}

\section{ABSTRACT}

In this essay we try to point out how the indiscipline, school violence and bullying have been focused in contemporary times. We also show that the medicalization and judicialization of life are concepts that in addition to gaining a greater visibility in society are a strong presence in the school environment. The networks that build the teaching seem to move the student condition in the background, prioritizing now, the identification of victims and aggressors. We conclude with the following points: (i) a certain disinvestment in the analysis of (in) discipline as an effect of the way school practices are organized and in the educational context changes (ii)enhancement of the concept of bullying;(iii) implication of security professionals in the process.

Keywords: Indiscipline, bullying, judicialization, medicalization.

\section{RESUMEN}


En este ensayo intentamos señalar cómo la indisciplina, violencia escolar y bullying se han centrado en contemporáneo. Mostramos también que la medicalización y judicialización de la vida son conceptos que además de ganar mayor visibilidad en la sociedad son una fuerte presencia en el ambiente escolar. Las redes que construyen la enseñanza parecen cambiar la condición del estudiante a una prioridad de segundo nivel, ahora, priorizando la identificación de las víctimas y de los agresores. Concluimos destacando los puntos siguientes: (i) desinversión en los análisis de (in) disciplina como una forma de organizar las prácticas de la escuela y los cambios de contexto educativo; (ii) elevación del concepto de bullying; (iii) implicación de profesionales de la seguridad en el proceso.

Palabras-clave: Indisciplina escolar, bullying, judicialización, medicalización.

\section{Introdução}

A dificuldade de lidar com os alunos nas escolas não é algo novo e, na atualidade, vem ganhando importância crescente, sendo apontada por educadores como uma das mais desafiantes tarefas a enfrentar nas salas de aula (Guimarães, 2005; 2006; Rocha \& Santos, 2011). Neste ensaio, buscamos abordar como a indisciplina, a violência e mais recentemente $o$ bullying têm sido apresentados como comportamentos que geram sérios obstáculos ao funcionamento das instituições escolares e ao desempenho acadêmico de alunos tanto de escolas públicas como de estabelecimentos privados. Discutimos também os efeitos dos processos de medicalização e de judicialização da vida, colocando em análise os modos como a escola vem lidando com essa dificuldade que ora aparece associada à patologia, ora à violência. Partimos do pressuposto de que quando a educação orienta suas forças para a elaboração de diagnósticos e prescrições de segurança o que ganha consistência no cotidiano escolar são expectativas e ações normalizadoras em que o adoecimento, a violência e o tão discutido bullying se constituem em uma produção generalizada, efeito de um processo centrado na prevenção do risco de (des) ordem.

As observações descritas acima nos conduzem ao questionamento em torno das peculiaridades que vêm cercando a escola. Esta instituição, segundo Foucault (1987), desde sempre se constituiu por meio da legitimação de ordens e normas e, ao mesmo tempo, por uma pluralidade de transgressões que são consideradas por muitos profissionais ligados à educação como impeditivas ao processo de formação (Heckert \& Andrade, 2010). Compreendemos que quando o foco das discussões é mantido sobre o tema como desvio que inviabiliza o processo educacional escolarizado, 0 que perde intensidade são as análises que evidenciam a complexidade dos fatores implicados nas situações escolares. Entre outros, podemos considerar o modo de organização do trabalho docente, as condições 
em que se realizam o ensino, as relações da escola com a comunidade...

Observamos também que a violência escolar, a indisciplina e o bullying são denominações utilizadas de modo diferenciado de acordo com o entendimento dos educadores e dos especialistas mobilizados pelo acontecimento. As medidas tomadas são justificadas pela ótica em que o fenômeno é visto segundo uma causalidade de ordem individual e/ou social, que podem ser classificadas como ato infracional, patologia ou irreverência (França, 1996; Guimarães, 2006; Moysés \& Collares, 2006). No entanto, antes de apresentar como tais conceitos vêm ganhando corpo em diferentes contextos convém explicitar que consideramos indisciplina um ato em desacordo com as regras e normas, ou seja, uma transgressão ao que está estabelecido, o que infringe a ordem. Já a violência entendemos que se trata de uma exacerbação da indisciplina, como o que causa dano físico ou moral ao(s) outro(s) ou a si próprio (Rocha, 2001; Guimarães, 2006). No que diz respeito ao bullying, estudiosos do tema (Marafon, Scheinvar \& Nascimento, 2014) citam Olweus, da Universidade de Bergen, Noruega, como precursor das investigações sobre o tema. Na Pesquisa Nacional de Saúde do Escolar (PeNSE) divulgada pelo Instituto Brasileiro de Geografia e Estatística (IBGE, 2009) encontramos nota explicando que:

O bullying (do inglês bully = valentão, brigão) compreende comportamentos com diversos níveis de violência que vão desde chateações inoportunas ou hostis até fatos francamente agressivos, sob forma verbal ou não, intencionais e repetidas, sem motivação aparente, provocado por um ou mais alunos em relação a outros, causando dor, angústia, exclusão, humilhação, discriminação, entre outros. (p.6)

Passamos, então, a diversidade de entendimento de tais conceitos que vem norteando ações controvertidas na Educação. Não é sem razão que Charlot (2005) alerta para o fato de que ao abordarmos a questão da violência na escola é preciso clareza sobre o que estamos ressaltando, inclusive para pensarmos quais as medidas que poderiam ser eficazes, pois tem sido comum o emprego dessa expressão para nomear comportamentos e acontecimentos distintos. Esse autor observa que, em muitos casos, designamos como violência atos que seriam de má-educação, ou padrões diferenciados dos que entendemos por boa-educação. Charlot (2005) reconhece ainda, que a instituição escolar é um local onde aparecem conflitos que de alguma forma podem ser confundidos com violência; portanto, não devemos almejar a erradicação destes, mas sim de certos formatos específicos. 
Para Devine (2002), amostragens probabilísticas, provenientes de questionários aplicados em larga escala, vêm direcionando prioritariamente as políticas públicas para prevenção de violência nas escolas sob o argumento de que os números traduzem fielmente 0 que se passa. Dessa forma, estatísticas possuiriam mais credibilidade do que estudos qualitativos produzidos em pequena escala. Alerta o autor para o grande número de programas de prevenção da violência nas escolas existentes nos Estados Unidos da América, desenvolvidos por diversas instituições e entidades não governamentais. $O$ pesquisador explica que são esses projetos que divulgam, ou que parecem autorizados a divulgar dados sobre violência nas escolas, transformando tais informações no que o autor denomina de "sabedoria convencional" (p.208) sobre o assunto. No que diz respeito ao bullying, notamos definições que não coincidem. Enquanto Hilário (2010, p.32), por exemplo, compreende que "não se restringe a atos verbais", citando como exemplo o tapa na cabeça que um determinado aluno receberia diariamente de outro colega quando ingressa na escola. Sacco, em entrevista (Paola, 2011) afirma que o "bullying é psicológico e verbal; quando alguém ataca, empurra etc, é crime" (p.29).

Segundo França (1996), a construção das margens do que é considerado como disciplina, aceitável ou preferível como comportamento de um grupo gera concomitantemente a indisciplina, o intolerável nas formas de convivência. A questão a ser priorizada é o modo de enfrentamento das adversidades: como matéria ética no exercício das instituições políticas ou expressão de um desvio, sintoma individual de que algo não vai bem, constituindo um caso clínico relativo aos aspectos privados da existência?

\section{Medicalizar e judicializar a vida escolar: causas ou efeitos de um processo?}

Medicalizar a vida se traduz em patologizar a sociedade e isto não está apenas ligado ao consumo crescente de substâncias psicoativas legais, mas, também, ao olhar classificatório dos sujeitos como possíveis portadores de transtornos frente às estatísticas estabelecidas. Na escola, a medicalização é um modo de ver e fazer a vida escolar que vem preponderando desde o século passado, trazendo especialistas para a rede de educação como psicólogos e neurologistas, entre outros (Moysés \& Collares, 2006). Assim, a infância tem sido submetida a diagnósticos para as dificuldades de aprendizagem, indisciplina, agitação, sem colocar em análise o contexto e as instituições que produzem a noção e padrões de desenvolvimento considerados normais. Por essa perspectiva, entram em cena os protocolos e procedimentos de avaliação (Machado, 
2007; Lessa, 2014) sendo que os mais comuns na atualidade são os psicológicos e os neurológicos que, com certa frequência, concluem pelos diagnósticos de diferentes transtornos como o déficit de atenção/hiperatividade (TDAH) e o de oposição e desafio (TOD) (Facci, Eidt, \& Tuleski, 2006).

Um atravessamento constante entre a medicalização e a judicialização dos corpos escolares tem ampliado o fôlego da lógica preventivo-assistencial que teve início na década de 1990 na sociedade norte americana, a qual passava por ondas de criminalidade. O discurso que ganhava ênfase trazia preocupações com o descontrole institucional, e a Medicina centrou suas pesquisas no que aparecia como distúrbios individuais, aos olhos da Ciência. Caliman (2009) aborda a questão a partir do estilo de pensamento da Psiquiatria, principalmente certa corrente norte americana que, através do Instituto Nacional de Saúde Mental daquele país, trabalhava na busca de soluções nacionais para a crescente violência social. O processo de biologização da Psiquiatria se generaliza na vida social, abrangendo o contexto escolar, constituindo uma nova lógica que se circunscreve em torno dos riscos gerenciáveis, cuja estratégia considerada mais eficaz será a farmacológica.

É importante ressaltar também que, recentemente, a denominada judicialização, ou seja, certa lógica jurídica, chega à escola como saída para seus velhos/novos problemas, ampliando o adoecimento e a medicalização de professores e alunos (Rocha \& Santos, 2011) na medida em que, como já assinalamos, a indisciplina como expressão das circunstâncias do ensinar e aprender escolarizado, resistência produzida nas relações do poder institucional, não entra em análise, ficando em evidência a tentativa de contenção de um processo que há muito não vai bem.

Nesse rumo de contenções se insere o crescente número de leis que vêm sendo promulgadas em diversos países sobre o bullying. No Brasil, em sete de julho de 2010, a Comissão de Educação e Cultura da Câmara dos Deputados aprovou a obrigatoriedade de escolas e clubes adotarem medidas de conscientização, prevenção, diagnóstico e combate ao bullying. Segundo informações da Agência de notícias da Câmara dos Deputados, de 02/08/2010, o texto aprovado foi o substitutivo que reuniu o PL 5.369/09, o PL 6.481/09 e o PL $6.725 / 10$. Cabe destacar que os dois primeiros projetos tratavam do combate ao bullying, enquanto o terceiro se referia ao combate à violência nas escolas. Naquela data, alguns estados e municípios brasileiros já possuíam leis específicas sobre o bullying, dentre eles o Rio Grande do Sul e Mato Grosso do Sul.

No Rio de Janeiro, em 20 de setembro de 2010 foi sancionada a Lei 5.824 que determina aos estabelecimentos de ensino e de saúde localizados no estado a obrigatoriedade de notificação à autoridade policial e ao Conselho Tutelar local dos casos de violência contra 
crianças e adolescentes, seja esta física ou não. Amplamente divulgada pela mídia como "a lei do bullying", a citada legislação, apesar de não fazer referência especifica ao termo, prevê sanções administrativas e legais àqueles que não procederem à notificação. $A$ nova lei estabelece, ainda, que a ausência de comunicação do fato à autoridade competente pode resultar em pagamento de multa por omissão que pode chegar à quantia de 20 salários de referência.

Ainda no ano de 2010, o Conselho Nacional de Justiça (CNJ) lançou a cartilha "Bullying", como parte do projeto denominado Justiça nas escolas. Na capa da publicação (Silva, 2010) encontra-se a justificativa de que "combater o bullying é uma questão de justiça: aprenda a identificar para prevenir e erradicar esse terrível fenômeno social". Na cartilha há afirmação de que o termo se refere aos "atos de violência (física ou não) (que) ocorrem de forma intencional e repetitiva contra um ou mais alunos que se encontram impossibilitados de fazer frente às agressões sofridas" (p.7); comportamentos esses que não apresentariam justificativas ou motivos. Essa publicação caracteriza o bullying como "universal e democrático" (p.12).

Albino e Terêncio (2009) afirmam que geralmente não questionamos sobre as verdadeiras causas do que se denomina de bullying. Os autores consideram que "os programas de prevenção e combate ao problema são vistos em um contexto limitado, desembocando geralmente em imperativos morais ou na defesa genérica do educar para a paz" (p.180). Esses pesquisadores chamam atenção para o fato de que $o$ ato infracional e a infração disciplinar não são sinônimos, ou seja, enquanto o primeiro se equipara à contravenção penal, 0 segundo se relaciona especificamente às normas estabelecidas pela escola. Reconhecem, portanto, que atualmente há uma busca por punição rigorosa para situações que deveriam ser encaminhadas no ambiente escolar. $\mathrm{Na}$ visão desses estudiosos, a escola deve estar atenta para que tais comportamentos não aconteçam, procurando solucionar a questão antes de encaminhar o conflito ao judiciário. Pode-se pensar, todavia, que a obrigatoriedade de notificação que advém da lei estadual promulgada no Rio de Janeiro dificulta a busca de soluções no ambiente escolar, pois estas passam a ser determinadas por outras instituições. De acordo com essa legislação caberia à escola apenas o diagnóstico do comportamento.

\section{Escola no contemporâneo: entre a macro e a micropolítica}

Para pensar a situação da escola na sociedade atual consideramos necessário, inicialmente, estabelecer parâmetros que deem visibilidade à malha constitutiva de sua lógica e de seu processo de 
consolidação. Já apontamos que a indisciplina, a violência e o bullying, como vivências desestabilizadoras, são considerados na atualidade como principais obstáculos ao bom desenvolvimento do processo de ensinar e aprender nas escolas. Rocha (2001) notou que as queixas caracterizadas como desvio, desrespeito ou infrequência ampliaram e a escola vem priorizando a generalização do controle das práticas como objetivo educacional, o que gera expectativas normalizadoras, além de multiplicar as demandas por encaminhamentos aos especialistas.

Em perspectiva semelhante, Debarbieux (2010) entende que existe uma forte correlação entre a forma de convívio mantida no estabelecimento e a violência escolar. Em entrevista publicada em número especial da Revista Sciences Humaines, denominado L'ecole en questions, o sociólogo explicita que "Não há possibilidade de trabalhar contra a violência escolar com equipes instáveis ou que não se entendem" (Debarbieux, 2010, s/p), considerando a necessidade de uma equipe que se constitua permanentemente a partir do processo de singularização da proposta da escola. Por esse motivo, o autor não acredita na eficácia de grandes programas nacionais a serem seguidos por todos, preferindo defender que os grupos locais adaptem tais referências à sua realidade.

Nos estabelecimentos educacionais contemporâneos não podemos nos esquecer de mencionar, ainda, os ditos equipamentos de segurança que já são usados (ou solicitados) como as onipresentes câmeras de vigilância, os cartões de identificação, os aparelhos que detectam metais, os aparelhos de raio-X para se verificar o conteúdo das mochilas e os sistemas de alarme, dentre tantos outros que se possa recordar. Devine (2002) chama atenção, por conseguinte, para a vultosa quantia destinada a programas de combate e prevenção de violência nas escolas. Além disso, podemos lembrar que, atualmente, a figura dos antigos inspetores de alunos vem sendo substituída por seguranças ou mesmo, em alguns países, por policiais. Quanto a esse dado, cabe ressaltar a polêmica criada pelo governo do estado do Rio de Janeiro ao assinar convênio com a Secretaria de Segurança, em 2012, no qual está prevista a contratação de policiais militares que estejam em horário de folga para atuarem, armados, dentro das escolas estaduais. Os policiais também estão autorizados a revistar os estudantes (O Globo, 2012).

Nessas situações, quando as questões de disciplina escolar são deslocadas dos profissionais da escola para os da área de segurança pode-se supor que as tarefas educacionais tomam outro rumo e, certamente, os educadores passam a ter mais dificuldades de fixar limites, pois perdem a legitimidade para lidar com a indisciplina, atribuição que não mais lhes pertence. Ganham terreno as soluções pragmáticas, que isolam educadores e individualizam questões, no lugar de se privilegiar uma discussão sobre as práticas coletivas. 
Em janeiro de 2016 o governador do Estado de São Paulo, Geraldo Alckmin, anuncia o nome do novo Secretário de Educação do Estado, após os inúmeros protestos e manifestações da população contra a reorganização escolar proposta pelo governo e ao pedido de demissão do antigo secretário. Foi empossado no cargo o ex-presidente do Tribunal de Justiça daquele estado, que acabara de concluir seu mandato no TJ em dezembro de 2015 (O Globo, 2016).

Percebemos, portanto, que a Educação acompanha, cada vez mais, o movimento acelerado na rede das grandes organizações sociais, privilegiando ligações funcionais e pragmáticas do professor com seu processo de trabalho: temporalidade em que ganha ênfase a competência enquanto execução do previsto, valorizando a competitividade, a produtividade e o cumprimento das normativas que estabelecem padrões, estatísticas e metas a serem cumpridas. Logo, a questão que se coloca para a escola é "de que modo esta pode 'dar conta' dos desafios impostos por uma sociedade que demanda disciplina e flexibilidade, abraçando e combatendo o que considera 'novo' em termos de tecnologias, práticas e valores" (Rocha \& Santos, 2011, p. 321). Que políticas vêm agenciando caminhos para a problematização das tensões circunscritas no cotidiano do trabalho escolar?

A vida na escola se constitui entre a macro e a micropolítica que são planos diferentes de vida e de análise, porém indissociáveis. A macropolítica, no entendimento de Guattari e Rolnik (1986, p.128), aborda a realidade como uma "função geral de equipamentos coletivos", agenciada no território social pelos costumes, mídia e leis como codificadores de comportamentos, de atitudes. Quando se trata da regulação do movimento escolar, encontramos dispositivos de homogeneização como projetos e organogramas que recortam 0 tempo/espaço configurando uma rotina de funcionamento de papéis e ritmos do trabalho que dão contorno às práticas, às expectativas, aos problemas e à formulação de questões que expressam parâmetros e modos de organizar a vida: O que tem esta criança? Por que é indisciplinada? Tais perguntas se direcionam a criança, preservando o prescrito para o exercício do trabalho escolar, para a cadência a ser imprimida nas atividades, estabelecendo "o" caminho investigativo. Ou seja, há uma realidade subjetiva da criança e uma objetiva do meio escolar que não nos leva às análises do tensionamento entre atores - aluno, professor e família - que estão em conflito com os referenciais e práticas pedagógico-institucionais. O que queremos sinalizar é que a fala é ato que intensifica forças, circunscrevendo o curso das ações, e se os pressupostos de verdade estão fixos e fragmentados, a lupa que dirige o olhar não produz um possível, senão "o" possível. Passamos a supor que nesta criança há algo que não vai bem e que precisamos investigar... investigar a criança, enquanto as práticas institucionais ficam fora das análises. 
Assim, a dimensão que está em jogo neste modo de enunciação é a da macropolítica e há um modelo estabelecido a ser seguido, há um padrão de normalidade instituído que nos serve de óculos para olhar os corpos e avaliá-los segundo a sua performance, pois quando perguntamos "Por que esta criança é agitada?" não é o ritmo priorizado como ideal para todos que entra em discussão e tampouco as relações que criam a cena e que dão movimento ao processo. Iluminamos um corpo e lhe atribuímos qualificação de agitado, agitado "em si" mesmo, corpo como portador de uma anormalidade, de um problema (disciplinar, neurológico,...) a ser pesquisado por especialistas.

A lógica de construção do problema que coloca atenção no corpo como um fragmento é a que dá suporte à patologização da sociedade, à medicalização no âmbito escolar, e aí temos uma variedade de medicamentos recomendados às crianças bem como solicitações de laudos e de terapias. E se a pergunta envolve o contexto da violência "Por que esta criança é violenta?" serão incluídas no cardápio de prescrições as medidas corretivas/preventivas como o encaminhamento ao Conselho Tutelar, ao Ministério Público, a instauração de círculos restaurativos, a intervenção junto às famílias, com a ênfase de que a justiça exerça os controles dos corpos que estão em desacordo com as relações e comportamentos esperados para os alunos.

No que diz respeito às ações designadas como bullying, comumente não há sequer questionamento a respeito de "como o aluno estaria praticando bullying", "em que circunstâncias?". Agora, de posse de cartilhas ou de outros informativos sobre o tema resta apenas a identificação da situação, passando-se rapidamente as medidas cabíveis às vítimas e aos agressores. Nesse sentido parece que, em um primeiro momento, já não há tanta necessidade de encaminhamentos para diversos especialistas que se incumbiriam de diagnosticar $o$ ocorrido. Como leis e cartilhas elencam comportamentos e práticas característicos de bullying, qualquer um poderia facilmente se incumbir do reconhecimento do quadro. Dessa forma, certos comportamentos que há algum tempo não passavam de provocações ou desentendimentos entre crianças, jovens e adultos, demandando ações diretas entre os atores em cena para a construção das relações de convivência, hoje facilmente são incorporados ao repertório do que é chamado de bullying, sendo solicitada a interferência da justiça, de organizações ou de profissionais que estão, em princípio, fora das situações escolares ou familiares.

Quanto à dimensão micropolítica de análise, esta se dá no plano das forças (sociais, políticas, jurídicas, institucionais, econômicas, pedagógicas...) que compõem um território existencial e que têm sido comprimidas em uma única forma de organizar o processo de ensinar 
e aprender, em uma única configuração dada como possível - no caso da escola, nas diretrizes que chegam a cada mandato como a legislação e os procedimentos para regular a vida de todas e de cada escola. É na micropolítica que se constitui o que escapa ao padrão delimitado e destoa da arrumação, sendo uma boa oportunidade de análise da multiplicidade de sentidos, dando consistência a um plano de imanência e fazendo a rotina dobrar de outras formas. Porém, quase nunca aproveitamos tais brechas em função da aceleração, da praticidade e do utilitarismo hegemônicos. É um trabalho político o de análise do que até o momento era impensado, impossível: O que é aprender? Como uma sala de aula cria um comum? O que afeta professores e alunos, implicando-os com o pensamento do que se passa? Como abrir o tempo a pulsações diferentes das queixas, das faltas, dos excessos, das eternas reclamações da precariedade de tudo, inclusive da escassez do tempo?

Como a dimensão micropolítica é pouco funcional à economia vigente porque demanda outro tempo de relações, de entendimento, rapidamente é capturada pela função que capitaliza (converte, capitaneia), atualizando forças em fatos há muito previstos. E é a criança quem vira "o" fato, "o" caso, "o agressor", "o infrator", personagem em desvio demandando uma rede de serviços da qual nós psis fazemos parte. Quando isso acontece temos um segundo efeito, a perda de legitimidade do professor para lidar com situações apresentadas pelos alunos e ainda um terceiro efeito, a magia de que todos os problemas serão resolvidos em algum Fórum, em algum consultório ou em vários, garantindo o sucesso da política de produtividade para um conjunto de especialistas. O que se constitui no limite da política pública estabelecida vira caso a ser avaliado, encaminhado, notificado. O modelo cega o olhar sobre alguém, mas faz aparecer o espectro como desvio a ser diagnosticado para ser reparado, corrigido, punido.

\section{Inconclusões}

Como apontamos ao longo deste ensaio, a indisciplina, a violência escolar e o bullying são conceitos que quando usados de forma indiferenciada dificultam uma análise aprofundada acerca do funcionamento da instituição escolar. Ressaltamos, também, que a medicalização e a judicialização presentes na sociedade contemporânea tomaram assento nos bancos escolares, centrando as lentes naqueles que agora são classificados como vítimas e agressores, deslocando a condição de aluno a um plano secundário.

O que tem mesmo essa criança? Podemos dizer que quando esta pergunta-afirmação direciona nossa atenção, concentra nosso olhar sobre a criança, sendo este o "olhar" que fortalece a normalização 
(Machado \& Souza, 1997) porque desencadeia controles entendidos como cuidados, prevenção, possibilidade de cura, punições, ações para dar conta do "caso", para reestabelecer a "paz". Ao procedermos dessa maneira, lá se vai mais uma chance de indagação curiosa sobre o que acontece entre nós desafiando a invenção do ensinar-aprender e a inclusão de um coletivo pensante-vivente.

Dessa forma, propomos iniciarmos pelo acontecimento, pelo que clama por atenção e abre às intervenções. Se, de um modo geral, as questões nos chegam pela criança, ela é o fio (pavio?) que traz a malha. E vale lembrar que sempre começamos pelo meio, é um tecer entre histórias, famílias, escolas, secretarias, postos de saúde, conselhos tutelares... políticas. Entendemos que devemos prestar atenção ao que o enunciado de uma pergunta aponta como verdade (Por que este aluno é violento?), aos valores que põe em circulação (o aluno é portador de uma essência patológica? É um infrator?) e aos efeitos que produz nos corpos (as ações se voltam para o aluno). Voltemos mais uma vez a cena para imprimir, então, deslocamento às ações: o que tornou possível o ato indisciplinado, a violência ou o que se chama de bullying? Que conflitos estariam presentes? Se estivermos atentos, talvez possamos derivar do lugar de socorro às emergências, girando a lupa da medicalização e/ou judicialização que as políticas contemporâneas põem em circulação, facultando uma responsabilização coletiva.

Estamos diante de mais perguntas do que de respostas. Percebemos que novos e velhos problemas na educação formal se reinstalam na lógica individualizante quando a indisciplina, resistência intrínseca às relações do poder institucional, não entra em análise. E o que deixa de ter visibilidade são as ações e circunstâncias, os modos de trabalhar e viver a formação, ampliando tarefas de contenção de todos os atores. Senão vejamos que o que vem sendo qualificado como violência ou como bullying advém de quadros apriorísticos de classificação cabendo à escola notificar aos profissionais que não fazem parte do contexto escolar, como se o fato não tivesse qualquer relação com o ambiente onde se passa.

Atualmente, as dificuldades que emergem no âmbito escolar permanecem no silêncio dos corpos, no lamento dos corredores ou nas agressões, nas licenças solicitadas pelos profissionais, nas fugas do espaço institucional que grita de angústia e adoecimento de alunos, professores, famílias e outros profissionais, inclusive psicólogos. Agora, a questão passa a ser de competência daqueles que integram a área de segurança e do judiciário ou de profissionais de saúde, restando aos trabalhadores da educação os encaminhamentos e as notificações do aluno para outros órgãos.

Assim, este ensaio traz como desafio para os profissionais ligados à educação o exercício do contratempo no cotidiano escolar que priorize o pensar as relações institucionais no trabalho do ensinar-aprender 
coletivo que se faz a cada vez, a cada nova situação - corpos em experimentação - , abrindo espaço aos avanços e retrocessos que nos colocam atentos à vida.

\section{Referências}

Agência Câmara de Notícias (2010, 02 agosto). Medidas contra o bullying mobilizam comissões da Câmara. Brasília: Câmara dos Deputados. Recuperado em 04 julho, 2011, de http://www2.camara.gov.br/agencia/noticias/educacao-ecultura/ 149877-medidas-contra-o-bullying-mibilizamcomissoes-da-camara.html

Albino, P. L., \& Terêncio, M. G (2009). Considerações críticas sobre o fenômeno do bullying: do conceito ao combate e à prevenção. Atuação - Revista Jurídica do Ministério Público Catarinense, 15, 169-195.

Caliman, L. V. (2009). A constituição sócio médica do "Fator TDAH". Psicologia \& Sociedade, 21(1), 135-144.

Charlot, B. (2005). A violência na escola: o que a escola pode fazer e como? Congresso americano sobre violências nas escolas (pp 127). Belém. Anais... Belém: Universidade da Amazônia.

Devine, J. (2002). A mercantilização da violência escolar. In E. Debarbieux, \& C. Blaya (Orgs.). Violência nas escolas e políticas públicas. (pp. 207-223). Brasília: Unesco.

Debarbieux, E. (2010). Pedagogie contre violence. Entretien avec Éric Debarbieux. Revue Sciences Humaines, 5, L'école em questions. Recuperado em 27 marco, 2011, de http: //www.scienceshumaines. com/pedagogie-contre-violenceentretien-avec-eric-debarbieux_fr_14902.html

Facci, M. G. D., Eidt, N. M., \& Tuleski, S̄. C. (2006). Contribuições da teoria histórico-cultural para o processo de avaliação psicoeducacional. Psicologia USP, 17(1), 99-124.

Foucault, M. (1987). Vigiar e Punir: nascimento da prisão. Petrópolis: Vozes.

França, S. (1996). A indisciplina como matéria do trabalho ético e político. In J. G. Aquino (Org.). Indisciplina na escola. Alternativas teóricas e Práticas. (pp. 139-148). São Paulo: Summus.

Guattari, F., \& Rolnik, S. (1986). Micropolítica. Cartografias do Desejo. Petrópolis: Vozes.

Guimarães, A. M. (2005). A Dinâmica da violência escolar: conflito e ambiguidade. 2 ed. Campinas: Editores Associados.

Guimarães, A. M. (2006). Escola: espaço de violência e indisciplina. Nas Redes da Educação, 1, 1-9. Recuperado em 15 maio, 2009, de http://www. lite.fae. unicamp.br/revista/guima.html 12/07/06 
Heckert, A. L. C., \& Andrade, R. B. (2010). Caminhos bifurcantes na educação inclusiva!Inclusões e rebeldias silenciosas na Educação Pública. Fractal: Revista de Psicologia, 22(3), 497512.

Hilário, L. A. (2010). Bullying: um novo desafio? Revista Jurídica Consulex, 325, 32-33.

Instituto Brasileiro de Geografia e Estatística (IBGE, 2009). Pesquisa Nacional de Saúde do Escolar (PeNSE), Rio de Janeiro: IBGE. Recuperado em 22 setembro, 2012, de http://www.ibge.gov.br/home/presidencia/noticias/noticia_impr essao.php?id_noticia $=1525$

Jornal O Globo. (2012, 03 de maio). MP questiona convênio que permite presença da PMs em escolas do Rio. Jornal O Globo. Rio de Janeiro. Recuperado em 03 maio, 2012, de http://oglobo.globo.com/rio/mp-questiona-convenio-quepermite-presenca-da-pms-em-escolas-do-rio-4801982

J ornal O Globo (2016, 22 de janeiro). Ex-presidente do TJ é o novo secretário de Educação de SP. Jornal O Globo, Rio de Janeiro. Recuperado em 22 janeiro, 2016, de http://oglobo.globo.com/brasil/ex-presidente-do-tj-o-novosecretario-de-educacao-de-sp- 18522150

Lei estadual 5.824/2010 de 20 de setembro. Altera o artigo 1ㅇ da lei no 4725, de 15 de março de 2006, e dá outras providências Recuperado em 03 maio, 2011, de http://alerjIn1.alerj.rj.gov.br/CONTLEI .NSF/c8aa0900025feef60 32564ec0060dfff/e2ae4fd54a98db61832577a5006598d5?Open Document

Lessa, P. V. (2014). O processo de escolarização e a constituição das funções psicológicas superiores: subsídios para uma proposta de avaliação psicológica. Tese de Doutorado. USP, São Paulo, SP. Brasil.

Machado, A.M., \& Souza, M. P. R. (1997). As crianças excluídas da escola: um alerta para a psicologia. In A. M. Machado, \& M. P. R. Souza. Psicologia Escolar: em busca de novos rumos. (pp. 35-49). São Paulo: Casa do Psicólogo.

Machado, A.M. (2007). Avaliação psicológica na educação: mudanças necessárias. In E.R. Tanamachi, M. P. R. Souza, \& M. L. da Rocha. Psicologia e Educação. Desafios teórico-práticos. (pp.143-167). São Paulo: Casa do Psicólogo.

Marafon, G., Scheinvar, E., \& Nascimento, M. L. (2014). Conflitos enquadrados como bullying: categoria que aumenta tensões e impossibilita análises. Psicologia Clínica, 26(2), 87-104.

Moysés, M. A. A., \& Collares, C. A. L. (2006). Medicalização: elemento de desconstrução dos direitos humanos. Recuperado em 07 maio, 2008, de 
http://www.crprj.org.br/documentos/2006-palestra-aparecidamoyses.pdf

Paola, F. (maio 2011). Anjos vingadores. Revista Cult, 28-30.

Rocha, M. L (2001). Educação e saúde: coletivização das ações e gestão participativa. In I. M. Maciel (Org.). Psicologia e Educação: novos caminhos para a formação. (pp. 213-229). Rio de Janeiro: Ciência Moderna.

Rocha, M. L., \& Santos, N. I. S. (2011). Micropolítica de inclusãoexclusão escolar: a indisciplina como analisador. Psicologia Social e seus movimentos: 30 anos de Abrapso. (pp. 217-337). Abrapso/Universitária da UFPE.

Silva, A. B. B. (2010). Bullying - cartilha 2010 - Projeto justiça nas escolas.

\section{Endereço para correspondência \\ Leila Maria Torraca de Brito}

Universidade do Estado do Rio de Janeiro

Rua São Francisco Xavier, 524, sala 10.001, bloco B, $10^{\circ}$ andar, Maracanã, CEP 20550-900, Rio de Janeiro - RJ, Brasil

Endereço eletrônico: leila.torraca.brito@gmail.com

Marisa Lopes da Rocha

Universidade do Estado do Rio de Janeiro

Rua São Francisco Xavier, 524, sala 10.001, bloco B, $10^{\circ}$ andar, Maracanã, CEP 20550-900, Rio de Janeiro - RJ, Brasil

Endereço eletrônico: marisalrocha@uol.com.br

Recebido em: 09/06/2015

Reformulado em: 26/01/2016

Aceito para publicação em: 31/03/2016

\section{Notas}

* Professora Associada do Instituto de Psicologia da Universidade do Estado do Rio de J aneiro (UERJ). Rio de Janeiro - RJ - Brasil.

** Professora Associada do Instituto de Psicologia da Universidade do Estado do Rio de Janeiro (UERJ ). Rio de Janeiro - RJ - Brasil. 